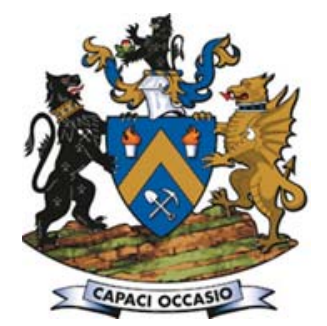

\title{
Distinguishing and controlling the key block structure of close-spaced coal seams in China
}

\author{
by S.R. Xie*, Y.J. Sun ${ }^{\dagger}$, S.S. He*, E.P. Li*, S. Gong*, and \\ S.J. Li*
}

\section{Synopsis}

Based on the complicated geological production conditions and abnormal strata behavior of the fully mechanized caving face No. 102 in the Xinyang Coal Mine, we analyze the breaking and forming process of distinguishing key block structures in close spaced coal seams. This analysis establishes an integrated mechanical model of these distinguishing structures. Furthermore, the horizontal force $T_{A B}$ generated by downward key blocks $A$ and $B$ is quantified, as is the Pressure $P_{G}$ exerted by key block $B$ on caved gangue. Finally, the interaction mechanism is revealed. Analysis of the results using Mathematica reveal the following: 1. Both $T_{A B}$ and $P_{G}$ exhibit approximately inverse relationships to coal pillar width $b ; 2 . T_{A B}$ exhibits an approximately exponential relationship with mining height $M$ of which the base is greater than $1 ; 3$. PG exhibits an approximately arctangent relationship with mining height $M$. Combining these results with field observations, we conclude that the area in the vicinity of supports $100 \#-120 \#$ in the upper area of working face No. 102 is the likely zone of abnormal strata behavior. Thus, this area was classified as a key control area. Based on these results, the graded support control technique is proposed. Application of this technique in the field resulted in a reduction in the rate of hydraulic support system malfunction from $47 \%$ to $7 \%$ in the key control area. In addition, during times of periodic mining pressure, the roof caving height value never exceeded $0.3 \mathrm{~m}$ and the maximum spalling depth never exceeded $0.2 \mathrm{~m}$. Overall, the results indicate that this new technique has markedly increased the stability of surrounding support rock material.

\section{Keywords}

close-spaced coal seams, distinguishing key block structure, graded supporting control, malfunction detection.

\section{Introduction}

Close-spaced coal seams are widely distributed in China, and mining proceeds from the uppermost to the lowermost seam (Zhang et al., 2008). In the case of coal seams in close proximity, a particular set of risk factors becomes pertinent. These include disturbance of lower seams during the mining of overlying ones and the decrease in mechanical stability of lower coal seams following repeated movement of key blocks in main coal seam roofs. This inevitably results in behaviour such as heavy wall spalling and support damage to fully mechanized caving faces in lower-lying coal seams, which necessitates a significantly increase in the measures to support surrounding rock material (Zhang et al., 2010; Huang et al., 2013; Xie et al., 2013).
In recent years, detailed research has been conducted on overlying strata behaviour and control methods. Zhu et al. (2010) established the 'granular media block' mechanical roof model for lower-lying coal seams and used it to analyse immediate roof structure stability and, ultimately, to derive mechanisms of roof collapse. Ju et al. $(2010,2013)$ studied seam support damage and dynamic mining pressure mechanisms while the lower working face crossed the tendencies of coal pillars, and proposed that both support damage and dynamic mining pressure should be attributed to the rotation of the top key blocks of boundary coal pillars. Wei et al. (2010) performed mechanical analyses of key block stability based on key strata control theory and identified three different forms of key strata instability in adjacent goafs. Hou and Li (2001) mechanically analysed the main roof structure formed by key blocks at different stages in a fully mechanized gob-side roadway driving process.

Most of the research to date has focused on analysing ordinary key block structure, and then proposing appropriate control methods. Research on structure with key blocks in different layers of rock strata, i.e. distinguishing key block structure, has seldom been undertaken.

Mining face no. 102 in the Xinyang coal mine was selected as the study site for this paper because of its particular overlying key block structure. Due to the mining sequence, the key blocks that resulted from mining activity at working faces no. 104 and no. 9102 in different rock layers comprise the distinguishing key block structure of mining face no. 102. Thus, the working mechanism of the distinctive key block structure is obviously

* College of Resources \& Safety Engineering, China University of Mining \& Technology, Beijing.

+ School of Mechanics and Civil Engineering, China University of Mining and Technology, Beijing.

(C) The Southern African Institute of Mining and Metallurgy, 2016. ISSN 2225-6253. Paper received Jul. 2014; revised paper received Feb. 2016. 


\section{Distinguishing and controlling the key block structure of close-spaced coal seams}

different from the ordinary key block structure. The structure was not taken into consideration during the preliminary support design process. Strong mining pressure was encountered above the working face, and the seam roof collapsed in places when certain hydraulic supports were damaged.

This research focused on the actual working mechanism and certain critical mechanical elements of this distinctive structure (i.e. stress and shear force). The aim of the research was to develop an appropriate control technique (which was ultimately named the 'graded support control method') and to test this technique at mining face no. 102.

\section{Engineering background}

Xinyang coal mine is located in Gaoyang town, which is 14 $\mathrm{km}$ from Xiaoyi in Shanxi Province. Mainly coal seams no. 9 and 10 , which are respectively $1.5 \mathrm{~m}$ and $7.8 \mathrm{~m}$ in thickness, are mined. The average separation between the seams is 0.43 $\mathrm{m}$. The seams are located at a depth of $300 \mathrm{~m}$, and dip at a shallow angle.

Mining face no. 102 is located beneath mining goaf no. 9102 and has a working face length of $220 \mathrm{~m}$. Thus, its immediate roof is comprised of caved stable gangue. Its main roof consists of limestone with a thickness of $9.26 \mathrm{~m}$ and its immediate floor consists of mudstone. The primary constituent of the main roof of mining face no. 9102 is limestone with a thickness of $8.95 \mathrm{~m}$. The lithological section of the fully mechanized caving face no. 102 is shown in Figure 1.

Work on the no. 9 and no. 10 coal seams of the adjacent mining face (no. 104) has been completed using a fully mechanized caving method. With a view to maximizing the coal recovery, the preparation roadways of mining face no. 102 were laid out so as to reduce the coal pillar width. The air return and haulage roadways were laid out $13 \mathrm{~m}$ and $20 \mathrm{~m}$ from the overlying goaf, respectively. The detailed roadway layout of mining face no. 102 and the adjacent mining area is shown in Figure 2.

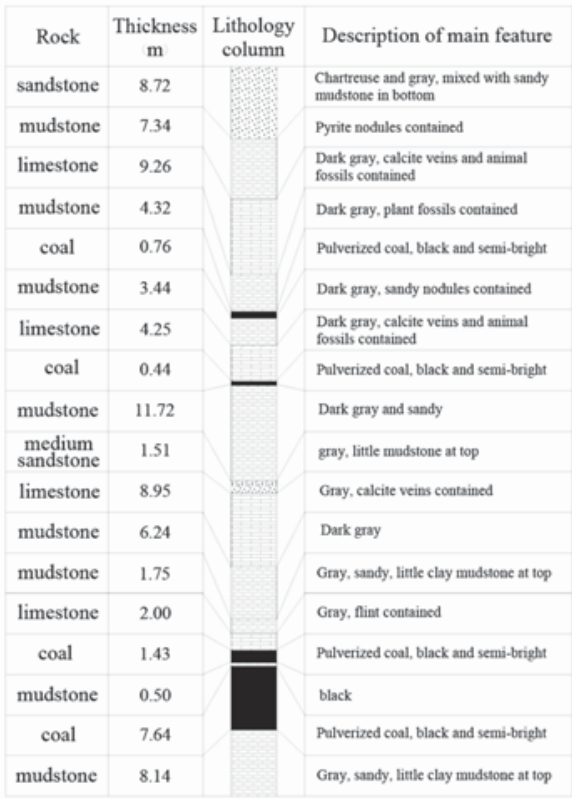

Figure 1-Lithological section of no. 102 fully mechanized caving face
Based on the specific geological conditions of mining face no. 102, the difficulties related to controlling strata behaviour and surrounding support rock stability can be summarized as follows:

- Strong strata behaviour was encountered frequently in some areas, and the support resistance reached $30 \mathrm{MPa}$ at times, even during the normal mining stage. When periodic mining pressure acted on the mining face, the safety valves installed in hydraulic support structures opened and the degree of column shrinkage was high

- Because a uniform support type was applied to the entire mining face, some supports functioned permanently at critical status with a limited allowance coefficient, which contributed to the incidents in the support surrounds

> If a particular support structure happened to leak (shown in Figure 3a), then adjacent supports could become overloaded as they absorbed the burden that the failed support had been bearing. Thus, the malfunction rate of support systems increased and overall support capacity decreased, resulting in largescale support failures

> Since the top coal was broken due to the impact of mining activity in goaf no. 9102, a roof collapse occurred under abnormal mining pressure (shown in Figure $3 b$ ) that initiated failure of the overhead support and heavy spalling on the coal wall of the mining face.
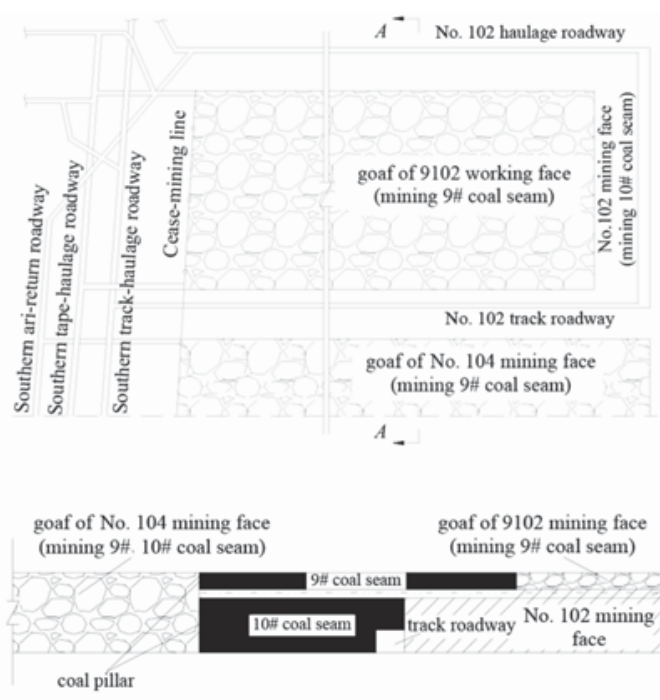

Figure 2-Roadway layout of no. 102 mining face and adjacent mining area

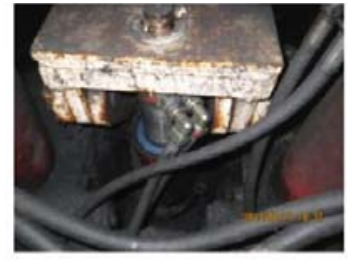

(a) support leakage

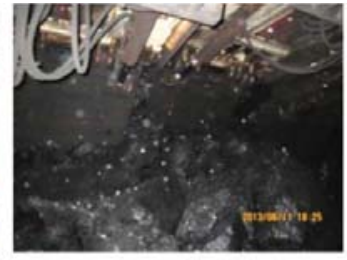

(b) roof falling accident
Figure 3-Abnormal strata behaviour in local area of no. 102 mining face 


\section{Distinguishing and controlling the key block structure of close-spaced coal seams}

\section{Distinguishing key block structure in close-spaced coal seams}

\section{Establishment of an integrated mechanical model}

The 'masonry structure model' of overlying strata explains the strata behaviour with respect to stope mining and provides an essential theoretical basis for strata control and support design. Using calculations based on this model, we concluded that the stratum located near the lower masonry structure was the $8.95 \mathrm{~m}$ thick limestone layer, which was $9.99 \mathrm{~m}$ away from the roof of mining face no. 9102 of the no. 9 coal seam. The stratum located by the upper masonry structure was the $9.26 \mathrm{~m}$ limestone layer, which was $45.38 \mathrm{~m}$ away from mining face no. 104 in both the no. 9 and no. 10 coal seams. These upper and lower masonry structures, located on two sides of the return air roadway coal pillar of mining face no. 102, formed adjacent key block structures that bear profound significance for mining face no. 102 . These structures produced a superposition influence area of abutment pressure on the side of the coal pillar. Moreover, the upper masonry structure generated an inclined stress (named $\sigma_{B^{\prime}}$ ) on key block $A$ at an angle $(\theta)$ to the vertical direction (Figure 4). The existence of this stress was verified, and its magnitude was shown to be high when the steel strip folded between the two roof anchors of the return air roadway for mining face no. 102. This stress was transmitted from the hinge point between key blocks $A$ and $B$ to key block $B$, and accounted for the changes that caused key block $B$ to act as caved gangue. It is clear from the above analysis that the strata behaviour and surrounding support rock control of mining face no. 102 is distinctive.

Given that the key blocks located within both the upper and lower masonry broke at the elastic-plastic boundary in the coal pillars, the distance between the broken line and the coal pillars is expressed as (Li, 2008):

$$
x_{0}=\frac{\lambda M}{2 \tan \varphi} \ln \left(\frac{k \gamma H+\frac{C}{\tan \varphi}}{\frac{C}{\tan \varphi}+\frac{P}{\lambda}}\right)
$$

where $x_{0}$ is the distance between the broken line and the coal pillars (in metres); $C$ is the coal cohesion strength (in $\mathrm{MPa}$ ); $\varphi$ is the internal friction angle (in degrees); $P$ is the support resistance of coal pillars (in $\mathrm{MPa}$ ); $M$ is the mining height at mining face no. $104 ; \lambda$ is the lateral coefficient; $k$ is the maximum concentrated stress coefficient; $\gamma$ is the average bulk density of the overlying strata (in $\mathrm{kN} / \mathrm{m}^{3}$ ); and $H$ is the average depth of the coal seams (in metres).

By substituting the parameters of mining faces no. 9102 and no. 104 into Equation [1] we obtain $x_{1}=5.2 \mathrm{~m}$, and $x_{2}=$ $18.4 \mathrm{~m}$. This means that the broken positions of key block $B$ and $\mathrm{B}^{\prime}$ in coal pillars are respectively $5.2 \mathrm{~m}$ and $18.4 \mathrm{~m}$ away from the side of the coal pillars.

By means of plastic limit analysis, the length of the arc triangle block is written as (Li et al., 2012c):

$$
L_{0}=L_{Z}\left(\sqrt{\left(L_{Z} / L_{M}\right)^{2}+3 / 2}-L_{Z} / L_{M}\right)
$$

where $L_{0}$ is the length of the arc triangle block (in metres); $L_{Z}$ is the periodic mining pressure distance (in metres); and $L_{M}$ is the length of the mining face (in metres).
By substitution of the same parameters as for Equation [1], the lengths of key block $B$ and $B^{\prime}$ are calculated as $24 \mathrm{~m}$ and $46 \mathrm{~m}$, respectively.

Furthermore, the integrated mechanical model of the distinguishing key block structure was established on the basis of the broken structure feature along mining face no. 102 and its neighbouring section, shown in Figure 4.

\section{Mechanical analysis of key block $A$}

Key block $A$ plays a role in transmitting force between key blocks $B$ and $B^{\prime}$ within the lower masonry structure, i.e. the force generated by rotation and subsidence of key block $B^{\prime}$ to block $A$ would act on block $B$. Therefore, the forcing status of key block $A$ has theoretical significance for integrated structure stability and strata behaviour at mining face no. 102. Furthermore, key block A is stable as a result of the combined action of lateral abutment stress BZ of mining face no. 9102, squeeze stress $\sigma_{B}$ from block $B^{\prime}$ to block $A$, supporting force $p$ from lower lying strata to block $A$, and $F_{B A}, T_{B A}$ from block $B$ to block $A$. These forces are illustrated in Figure 5.

According to elastic-plastic limit equilibrium theory, vertical stress at an arbitrary point in the limit equilibrium area is expressed as (Xie, Yang, and Liu, 2006):
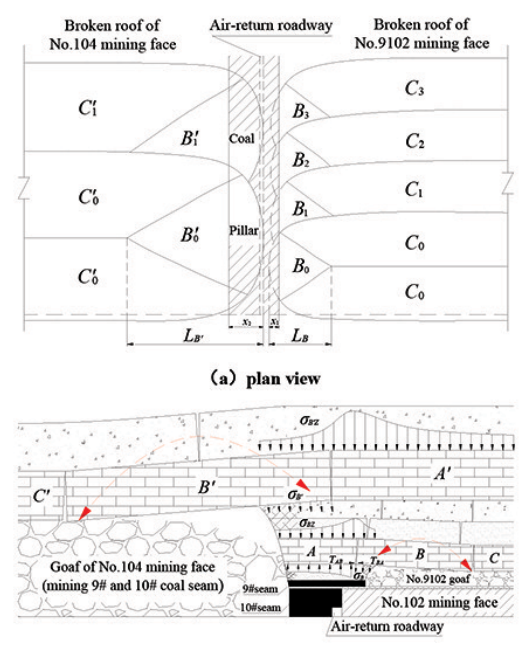

(b) section view

Figure 4-Integrated mechanical model of key block structure

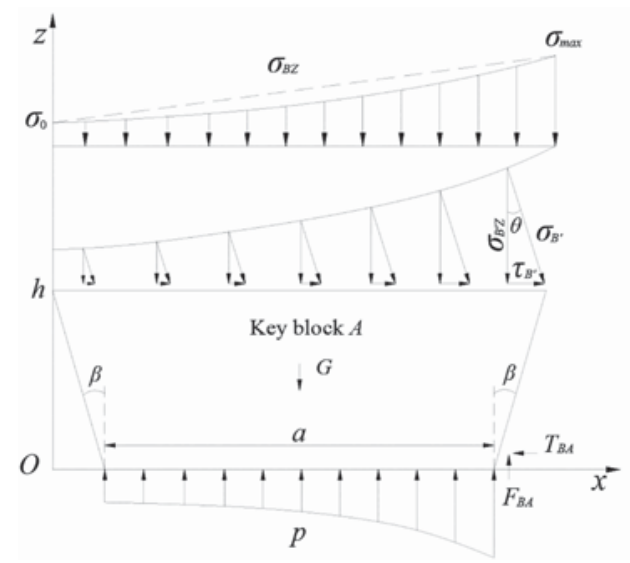

Figure 5-Force analysis figure of key block A 


\section{Distinguishing and controlling the key block structure of close-spaced coal seams}

$$
\sigma_{z}=\frac{P \tan \varphi+\lambda C}{\lambda \tan \varphi} e^{\frac{2 \tan \varphi}{M \lambda} x-\frac{\tan ^{2} \varphi}{2 \lambda}}
$$

Given that the lateral abutment stress borne by key block A at mining face no. 9102 is regarded as linear and nonuniform, Equation [3] could be written as:

$$
\sigma_{B Z}=\frac{\sigma_{\max }-\sigma_{0}}{a+2 h \tan \beta} x+\sigma_{0}
$$

where

$$
\begin{aligned}
& \sigma_{\max }=\frac{P \tan \varphi+\lambda C}{\lambda \tan \varphi} e^{\frac{4(a+2 h \tan \beta) \tan \varphi-m \tan ^{2} \varphi}{2 \lambda m},} \\
& \sigma_{0}=\gamma H .
\end{aligned}
$$

where $\sigma_{B Z}$ is the lateral abutment stress of mining face no. 9102 (in $\mathrm{MPa}$ ); $h$ is the main roof thickness of mining face no. 9102 (in metres); $m$ is the mining height of face no. 9102 (in metres); $a$ is the bottom strength of key block $A$ (in metres); $a=b-x_{1} ; b$ is the coal pillar width between mining faces no. 104 and no. 9102 (in metres); $x_{1}$ is the distance between the broken line of key block $B$ and the side of the coal pillar (in metres); and $\beta$ is the angle between main roof broken line of no. 9102 mining face and vertical direction. Then,

$$
\left\{\begin{array}{l}
N_{B}=\int_{0}^{a+2 h \tan \beta} \sigma_{B Z} L_{Z B} d x \\
N_{B^{\prime}}=\int_{0}^{a+2 h \tan \beta} \sigma_{B^{\prime} Z} L_{Z B} d x \\
N_{P}=\int_{h \tan \beta}^{a+h \tan \beta} p L_{Z B} d x \\
Q_{B^{\prime}}=\int_{0}^{a+2 h \tan \beta} \tau_{B^{\prime}} L_{Z B} d x
\end{array}\right.
$$

where $N_{B}$ is the abutment stress from block $B$ to block $A$ (in $\mathrm{kN}$ ); $N_{B}$ is the abutment stress from block $B$ to block $A$ (in $\mathrm{kN}) ; N_{P}$ is the supporting force from lower lying strata acting on block $A$ (in $\mathrm{kN}$ ); $Q_{B}$ is the shear force from block $B^{\prime}$ on block $A$ (in $\mathrm{kN}$ ); $\sigma_{\mathrm{B}^{\prime} \mathrm{Z}}$ is the normal component of the squeeze force from block $B^{\prime}$ on block $A$ (in $\mathrm{MPa}$ ); $\tau_{B}$ is the tangential component of the squeeze force from block $B^{\prime}$ on block $A$ (in $\mathrm{MPa}) ; p$ is the pressure exerted by block $A$ on lower lying strata (in $\mathrm{MPa}$ ); and $L_{Z B}$ is the strike width of block $B$ (in metres).

The balance equation obtained from the force analysis of block $A$ (see Figure 5 ) is expressed as:

$$
\left\{\begin{array}{l}
N_{B}+N_{B^{\prime}}-N_{P}+G-F_{B A}=0 \\
Q_{B^{\prime}}-f-T_{B A}=0
\end{array}\right.
$$

As $F_{B A} / T_{B A}$ and $F_{A B} / T_{A B}$ have the same value but work in opposite directions, $F_{B A}$ and $T_{B A}$ are obtained as follows:

$$
\begin{aligned}
& F_{A B}=F_{B A}=N_{B}+N_{B^{\prime}}-N_{P}+G \\
& T_{A B}=T_{B A}=Q_{B^{\prime}}-f
\end{aligned}
$$

where

$$
\left\{\begin{array}{l}
G=\gamma h L_{Z B}(a+h \tan \beta) \\
\tau_{B^{\prime}}=\sigma_{B^{\prime} Z} \tan \theta \\
\tan \theta=\Delta_{B^{\prime}} / L_{B^{\prime}} \\
\Delta_{B^{\prime}}=M-\left(K_{p}-1\right) \sum h_{1}
\end{array}\right.
$$

where $\Delta_{B^{\prime}}$ is the degree of subsidence of key block $B^{\prime}$ (in metres); $L_{B}$ is the length of key block $B^{\prime}$ (in metres); $\sum_{h 1}$ is the immediate roof thickness of mining face no. 104 (in metres); $K_{p}$ is swell coefficient of the immediate roof; and $\mu$ is the dynamic friction coefficient between block $A$ and updown strata.

Using the MathematicaTM software package, the variation of the horizontal force $T_{A B}$ with mining height $M$ of mining face no. 104 and coal pillar width $b$ is acquired as shown in Figure 6.

The following conclusions can be drawn from Figure 6 .

$>T_{A B}$ displays an approximately inverse relationship with coal pillar width $b$ and an exponential relationship with mining height $M$ of which the base is greater than 1

> $T_{A B}$ is hardly affected at low values of $M$ and $b$

$>T_{A B}$ increases with increasing $M$. The rate of increase becomes greater as $M$ increases, but decreases when $b$ increases as well

$>T_{A B}$ decreases as $b$ increases. Furthermore, the rate of decrease reduces with increasing $b$ and $M$

> $T_{A B}$ increases dramatically when $M \geq 10 \mathrm{~m}$ and $b \leq 10$ $\mathrm{m}$. Furthermore, the rotation angle of block $\mathrm{B}^{\prime}$ becomes larger and more intense as a strong horizontal compressive force is generated. Hence, the conditions could arise for block $A$ to move, which would result in a stronger horizontal force on block $B$.

\section{Mechanical analysis of block B}

\section{Mechanical model}

As seen from Figure 4, the broken-off lower and inferior strata on the right-hand side of the return air roadway formed key block $B$ after work on mining face no. 9102 was complete. Block $B$ would rotate and sink around the $E F$ axis, and then constitute a stable structure with blocks $A$ and $C$ when it reached a certain position. Meanwhile, key block $B$ is stable because of the joint action of the vertical force $F_{A B}$ from block $A$ to block $B$, the vertical force $F_{C B}$ from block $C$ to block $B$, the supporting force $F_{C B}$ from the coal pillars, and supporting force $F_{G}$ from the gangue to bear the force $F_{Z}$ from the overlying strata.

For calculation convenience, some simplifications are made with respect to block $B$ as follows:

> Key block $B$ is considered as an isosceles triangle, so $\angle \mathrm{DGH}=\angle \mathrm{GDH}=\alpha$, where $\alpha=\arctan \left(2 L_{B} / L_{Z B}\right)$

$>$ A pair of forces $F_{C B}$ in the strike direction have the same value; the acting points are respectively at the midpoint of $G H, D H$, and $C H=S / 2$, where $s$ is the occlusal length

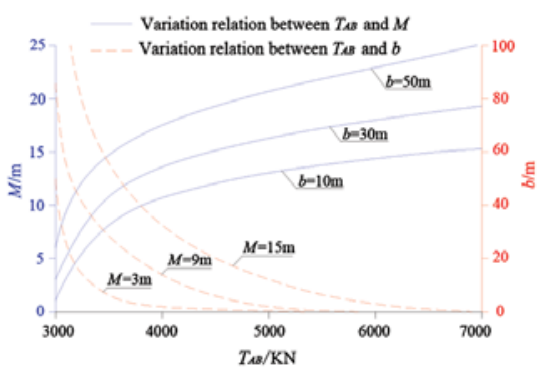

Figure 6-Relationship between $T_{A B}$ and $b$ 


\section{Distinguishing and controlling the key block structure of close-spaced coal seams}

The acting point of $T_{A B}$ is the midpoint of $E F$, and $E B^{\prime}=S / 2$

The acting point of $F_{Z}$ is the barycentre of block $B$. By applying the above simplifications, a mechanical model of block B was constructed (see Figure 7).

\section{Gangue contacting position of block $B$ and its range}

Structure subsidence $s_{0}$ and rotation subsidence $x \sin \theta$ combine to result in the total subsidence of block $B_{s x}$, and

$$
s_{x}=s_{0}+x \sin \theta
$$

where, $S_{x}$ is total subsidence (in metres); $S_{0}$ is structural subsidence (in metres); and $\theta$ is rotation angle (in degrees).

The gangue compression of goaf $s_{y}$ is expressed as:

$$
s_{y}=s_{x}-\left[m-\left(K_{p}-1\right) \sum h_{2}\right]
$$

where $s_{y}$ is the gangue compression of goaf no. 9102 (in metres); and $\sum h_{2}$ is the immediate roof thickness of mining face no. 9102 (in metres).

Combining Equations [10] and [11], the rotation angle of block $B$ at the inception of gangue contact is expressed as:

$$
\theta_{0}=\arcsin \left(\frac{m-\left(K_{p}-1\right) \sum h_{2}-s_{0}}{L_{B}}\right)
$$

where $L_{B}$ is the tendency length of block $B$ (in metres).

If $\theta \leq \theta_{0}$, this indicates that block $B$ does not make contact with the gangue, and that block $B$ is therefore not subjected to forces as a result of fallen gangue, i.e. $F_{G}=0$. If $\theta>\theta_{0}$, this indicates that block $B$ does have contact with the gangue.

Given that $s_{y}=0$, the threshold abscissa for the contact of block $B$ with the gangue is expressed as:

$$
x_{3}=\frac{m-\left(K_{p}-1\right) \sum h_{2}-s_{0}}{\sin \theta}
$$

and the contact zone is $[c, d]$, where

$$
\left\{\begin{array}{l}
c=x_{3}+15 \\
d=L_{B}+15
\end{array}\right.
$$

Substituting parameter values pertaining to mining face no. 9102 into Equation [14], the values of $c$ and $d$ are found to be $32.6 \mathrm{~m}$ and $49.8 \mathrm{~m}$, respectively. Because of the stress transmission angle, the area of increased stress area is calculated as occurring from $23.6-58.8 \mathrm{~m}$ from the return air roadway of mining face no. 102, which coincides with the theoretically significant area of efficient strata control.

To investigate the abnormal strata behaviour of mining face no. 102, on-site observation was undertaken for one month. Aspects that were monitored included support resistance value, degree of spalling, and degree of roof collapse. Results were analysed statistically. Results show that the support resistance value in the normal area is $<25$ $\mathrm{MPa}$, but it exceeds $30 \mathrm{MPa}$ in the area containing supports $100-120$, where the opening ratio of safety valves exceeds $30 \%$. More importantly, spalling and roof collapse frequency are especially high in the 100-120 support area, whether mining pressure increases periodically or not. Therefore, we concluded that the area containing supports $100-120$ is the critical area for mining face no. 102.

\section{Load on block $B$}

Lateral abutment stress will be generated on the coal pillar side when the work on mining face no. 104 is complete. Furthermore, the lateral abutment stress gradually increases in the limit equilibrium area and tends to stabilize as mining height $M$ increases (Cheng et al., 2012). Equations [1] and [3] suggest that the scale of the limit equilibrium area increases with mining height $M$; however, the peak lateral abutment stress value decreases with $M$. It is also calculated that key block $B$ is located in the stress attenuation area after peak lateral stress is reached (see Figure 8).

$F_{Z}$ acting on block $B$ is derived as follows.

$$
F_{Z}=\frac{L_{Z}}{L_{B}} \int_{0}^{L_{B}} q(x)\left(L_{B}-x\right) d x
$$

As seen from Figure 8, although the peak lateral abutment stress value decreases with increasing mining height $M$, the attenuation ratio tends to be greatly reduced in the elastic area. Furthermore, the range of influence obviously increases, and hence the distributed lateral abutment press $q(x)$ increases. Thus, $F_{Z}$ increases with mining height $M$ (see Figure 8).

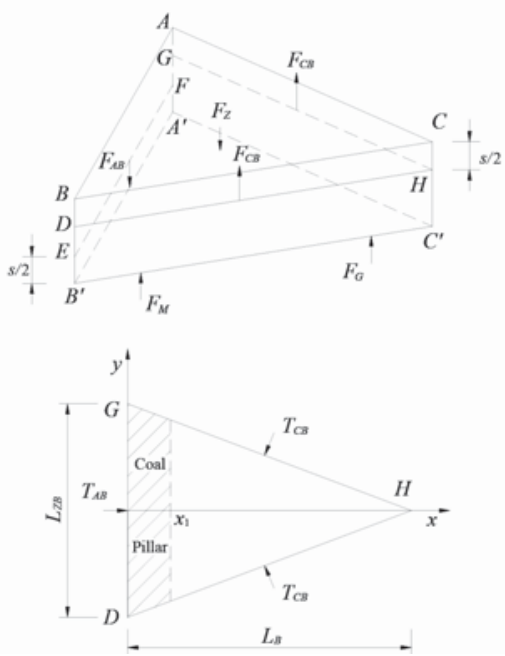

Figure 7-Analysis of forces acting on key block $B$

\section{Supporting force of coal pillars to block $B$}

The rotation and subsidence of block $B$ results in a compressional force that acts on the coal pillar. As the coal pillar is broken under the influence of this of lateral stress, the relationship between the force and the strain on the coal pillar is not linear but exponential. The compression curve is expressed as (Qian et al., 1990):

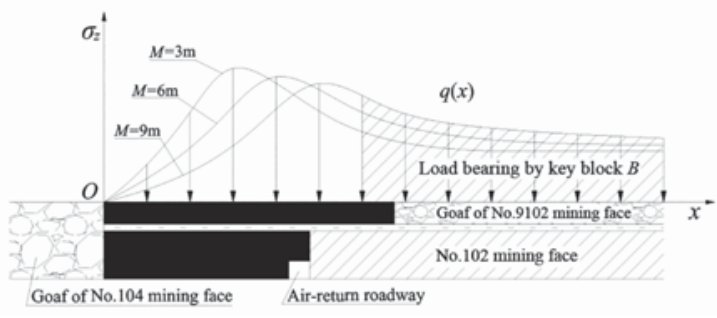

Figure 8-Relationship between $F_{Z}$ and $M$ 


\section{Distinguishing and controlling the key block structure of close-spaced coal seams}

$$
\sigma=K \varepsilon^{n}
$$

where

$$
\varepsilon=\frac{s_{0}}{m+\sum h_{2}}
$$

Here, $K$ is a compression modulus (in $\mathrm{MPa}$ ) and $n$ is a squeeze exponent (for broken media, $n=3$ ).

Then, the supporting force $F_{M}$ as a result of the caving gangue acting on block $B$ is expressed as:

$$
F_{M}=\int_{0}^{x_{1}} \sigma\left[\frac{2}{\tan \alpha}\left(L_{B}-x\right)\right] d x
$$

Because $F_{Z}$ increases with $M$, structural subsidence $s_{0}$ also increases, as does compressional strain $\varepsilon$.

\section{Force of block $B$ on caving gangue}

When block $B$ rotates to make contact with the gangue, the majority of its gravitational and bearing load is borne by gangue from mining face no. 9102. Thus, the extent and magnitude of this force will directly influence the strata behaviour of mining face no. 102 .

Equilibrium equations are obtained by mechanical analysis of block $B$ (shown in Figure 7 ).

$$
\begin{aligned}
& 2 F_{C B}+F_{M}+F_{G}-F_{A B}-F_{Z}=0 \\
& T_{A B}=2 T_{C B} \cos \alpha
\end{aligned}
$$

Then, the equilibrium moment equation of block $B$ with respect to axis $E F$ is expressed as:

$$
\begin{aligned}
& F_{M} g \frac{x_{1}}{2}+F_{G} g\left(\frac{L_{B}+x_{3}}{2}\right)+2 F_{C B} g \frac{L_{B}}{2}- \\
& 2 T_{C B} \cos \alpha g\left(\Delta_{B}-s\right)-F_{Z} g \frac{L_{B}}{3}=0
\end{aligned}
$$

Combining Equations [19], [20], and [21], we obtain:

$$
F_{G}=\frac{\sin \theta}{\Delta_{B}-s_{0}}\left[\begin{array}{l}
2 T_{A B}\left(\Delta_{B}-s\right)+F_{Z} L_{B} / 3 \\
+F_{M}\left(L_{B}-x_{1}\right)-F_{A B} L_{B}
\end{array}\right]
$$

where

$$
\left\{\begin{array}{l}
s=\left(2 h-L_{B} \sin \theta\right) / 4 \\
\Delta_{B}=m-\left(K_{p}-1\right) \sum h_{2}
\end{array}\right.
$$

Here, $\Delta B$ is the degree of subsidence of block $B$ (in metres) and $s$ is occlusal length among blocks $A, B$, and $C$ (in metres).

The force per unit area $P_{G}$ exerted by block $B$ on the gangue is expressed as:

$$
P_{G}=F_{G} / S_{G}
$$

where

$$
S_{G}=\frac{L_{Z B}\left(L_{B}-x_{3}\right)}{2 L_{B}}
$$

and where $S_{G}$ is the area of contact with the gangue (in $\mathrm{m}^{2}$ ), and $L_{Z B}$ is the periodic mining pressure distance of no. 9102 mining face.

As seen from Equation [25], $P_{G}$ is related to the mining height $M$ of mining face no. 104 and to the width $b$ of the coal pillars. Using the Mathematica software package, the relationship of $P_{G}$ to $M$ and $b$ was plotted graphically and is presented in Figure 9.

Some conclusions that can be drawn from Figure 9 are as follows.

> $P_{G}$ has an approximately inverse relationship with $b$ and an approximately arctangent relationship with mining height $M$

- $P_{G}$ is barely influenced when the values of $M$ and $b$ change

$>P_{G}$ increases with $M$, and the ratio of increase is initially rapid but then slows

> $P_{G}$ decreases as $b$ increases. The decrease is initially rapid, and then slows with further increases in $b$.

The intersection points of the two curves move toward the upper right as $M$ increases, and toward the upper left as $b$ increases.

Using the values of $M=9 \mathrm{~m}$, and $b=40 \mathrm{~m}$, and by means of the interpolation method presented in Figure $9, P_{G}$ is calculated to be approximately $33 \mathrm{MPa}$, which means that the support pressure value in the mid-upper area is $33 \mathrm{MPa}$ without periodic mining pressure. The corresponding working resistance is $5300 \mathrm{kN}$. When $M$ approaches zero and $b$ approaches infinity, $P_{G}$ asymptotically approaches a value of $27 \mathrm{MPa}$. Furthermore, mining face no. 102 is marginally influenced by mining face no. 104, which suggests that the support pressure for no. 102 mining face is approximately $27 \mathrm{MPa}$ without periodic mining pressure. The corresponding support working resistance under such conditions is $4700 \mathrm{kN}$.

Through data analysis, the dynamic loading coefficient is calculated to be 1.15 , which implies a working resistance of $5400 \mathrm{kN}$ to sustain support in normal areas and $6100 \mathrm{kN}$ to sustain support in key areas. The support type (ZF6800/17/32) at mining face no. 102 has an estimated working resistance of $6800 \mathrm{kN}$. Thus the allowance coefficients for key and normal areas are 1.3 and 1.1, respectively.

With the aim of reducing support rock failure incidents in key areas and in order to improve support overhaul efficiency, the authors propose the graded supporting control technique.

\section{Graded supporting control technique for support- surrounding rocks}

The graded support control technique begins with the categorization of the supportive units of a mining face into distinct key areas and normal areas. The technique then advocates specific, targeted control approaches for support units in these different areas. Thus, it successfully avoids excessive

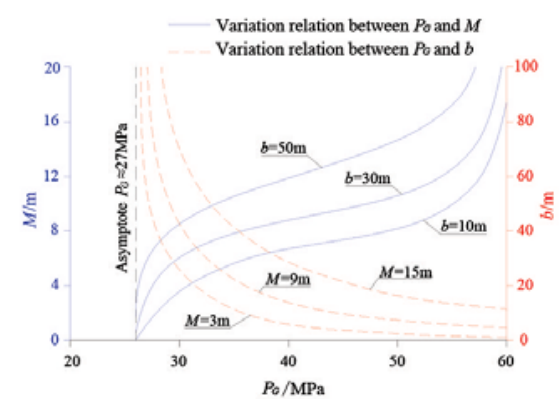

Figure 9-Relationship between $P_{G}$ and $M$ and $b$ 


\section{Distinguishing and controlling the key block structure of close-spaced coal seams}

overhauling work on the whole mining face, as well as the application of inappropriate control efforts in key areas. The overhaul programme and interrelated indices are discussed with the aim of achieving safe and efficient control of a mining face's surrounding support material.

\section{Discussion on control indexes of support-surrounding rock in No.102 mining face}

Research shows that the working resistance of support brackets and their distance from the working face (supportface distance) are important factors affecting the stability of a working face's surrounding rock material (Xie et al., 2013). Control indices, based mainly on working resistance and support-face distance, can be determined based on the above theoretical calculation and numerical simulation result. Based on the actual geological and production parameters at mining face no. 102, and by means of UDEC software, a numerical calculation model has been established, allowing the roof collapse scenario to be simulated under different values of theoretical working resistance and support-face distance. It should be noted that reducing the falling height of rock material to $<0.3 \mathrm{~m}$ is considered a sufficient control effort.

\section{Control index in key area}

The acceptable range of working resistance values is calculated to be $4900-5700 \mathrm{kN}$ with an interval value of $200 \mathrm{kN}$. The acceptable range of support-face distances is calculated as $0-1.00 \mathrm{~m}$ with an interval value of $0.25 \mathrm{~m}$. There are 25 combinations of working resistance and support-face distances represented along mining face no. 102 (see Figure 10). Figure 10 shows that when the support-face distance remains constant, the roof falling height reduces as working resistance increases. However, while working resistance remains constant, the roof falling height increases along with the support-face distance. This tendency is especially marked when the support-face distance exceeds $0.5 \mathrm{~m}$. The reasonable and critical value combination of working resistance and support-face distance in key area emerges as $5300 \mathrm{kN}, 0.5 \mathrm{~m}$.

\section{Control indices in normal areas}

Given that few supporting brackets in the normal areas would be affected by the distinguishing key block structure, the critical values in the simulation of normal area conditions are considered to be smaller than those for key areas. Thus, the acceptable range of working resistance values is defined as $4300-5100 \mathrm{kN}$ with an interval value of $200 \mathrm{kN}$. The range of acceptable support-face distances is set as 0-1.00 $\mathrm{m}$ with an interval value of $0.25 \mathrm{~m}$. Simulation results according to these value ranges are shown in Figure 11. By means of the

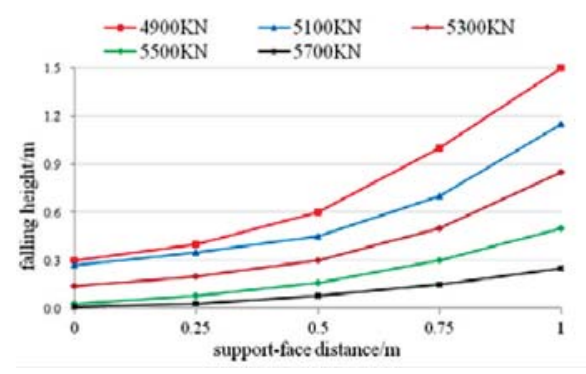

Figure 10-Simulation of control indexes in key area same process of analysis applied to key areas, the reasonable and critical value combination of working resistance and support-face distance is $4700 \mathrm{kN}, 0.75 \mathrm{~m}$.

\section{Graded malfunction detection and support control}

A detector for leakage malfunctions in hydraulic support systems has been developed (Xie et al., 2013; He et al., 2013) and is shown in Figure 12.

In essence, the detector makes use of a high-frequency acoustic sensor and a high-sensitivity piezoelectric accelerometer to detect leakage signals emitted by the hydraulic support system. Its effective detection distance is > $80 \mathrm{~cm}$ and its frequency is $10-40 \mathrm{kHz}$. The detector can instantly detect leakages in hydraulic support systems and accurately locate them, thus timeous overhaul work can be undertaken. The above features of the detector are obviously essential in maintaining key area support as even minor leakages in these areas could induce insufficient working resistance. Inadequate working resistance is likely to culminate in a wide range of spalling and roof collapse incidents and could even lead to surrounding support rock accidents.

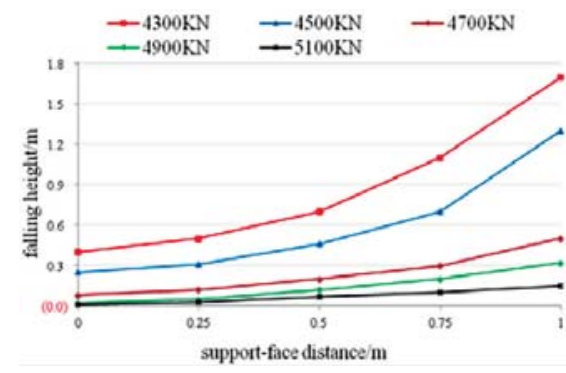

Figure 11-Simulation of control indexes in normal area

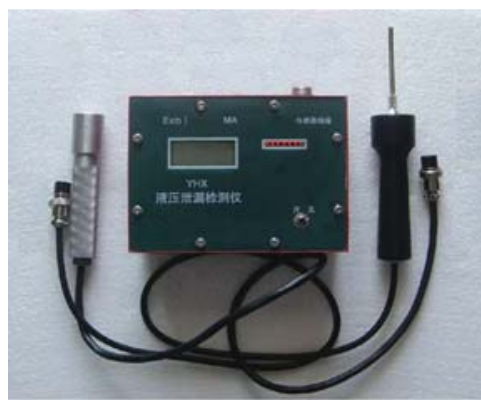

Figure 12-YHX hydraulic leakage detector

\section{Table}

Graded overhaul programme for no. 102 working face

\begin{tabular}{|l|c|c|c|}
\hline \multirow{2}{*}{ Overhaul area } & Overhaul frequency & Malfunction & Overhaul level \\
\hline \multirow{2}{*}{ Key area } & \multirow{2}{*}{ Two days } & Minor & Timely \\
\cline { 3 - 4 } & & Moderate & Immediately \\
\cline { 3 - 4 } & & Serious & Immediately \\
\hline Normal area & One week & Minor & Timely \\
\cline { 3 - 4 } & & Moderate & Timely \\
\cline { 3 - 4 } & & Serious & Immediately \\
\hline
\end{tabular}




\section{Distinguishing and controlling the key block structure of close-spaced coal seams}

Through field experience, the diagnostic criteria for determining leakage levels are summarized as follows: normal ( $Z \leq 25)$; minor $(25<Z \leq 500)$; moderate $(500<Z \leq 1000)$; and serious leakage $(Z>1000)$. According to strata behaviour distribution laws and the working resistance conditions of mining face no. 102, minimum detection frequencies and overhaul degrees were determined for key and normal areas. This was done in order to avoid unnecessary overhaul work in normal areas and untenable instability in key areas, and to ensure functional and cost-effective support maintenance.

The proposed graded overhaul programme for mining face no. 102 is shown in Table I. It is advisable that one complete overhaul be carried out while the periodic mining pressure is in action.

\section{Field practice}

Through application of graded support control techniques, overhaul work is markedly reduced. The malfunction ratio in key areas decreases from $45 \%$ to $14 \%$, and roof collapse accidents decrease in frequency as well. The malfunction ratio in normal areas decreases from $28 \%$ to $8 \%$, and the roof collapse ratio decreases from $46 \%$ to $12 \%$. An example of actual control work is depicted in Figure 13.

Thus, application of this approach in the field proves the efficiency of the graded supporting control technique in improving safety of work spaces, greatly decreasing the overhaul workload and eliminating overhaul blindness.

\section{Conclusions}

Distinguishing key block structures are formed above the return air roadway of mining face no. 102. The inclined stress $\sigma_{B^{\prime}}$ of key block $A$ is generated by the upper masonry structures and then transmitted to key block $B$. Thus, the combination of forces acting on block $B$ is changed, as is its relationship to gangue dynamics. The combined action of $\sigma_{B}$ and superpositional abutment stress results in abnormal strata behaviour in the vicinity of mining face no. 102.

An integrated mechanical model of key blocks located in different layers was established, and the horizontal force $T_{A B}$ acting between blocks $A$ and $B$ was quantified. Analysis using Mathematica software revealed that $T_{A B}$ exhibits an approximately inverse relationship with the width of the coal pillar $b$ and an approximately exponential relationship with the mining height $M$ of which the base overruns 1 .

A mechanical model of the forces acting on block $B$ was established and the pressure $P_{G}$ exerted by block $B$ on the caved gangue calculated. Using Mathematica software, $P_{G}$ was calculated as having an approximately inverse relationship with $b$ (width of coal pillars) and an approxi-

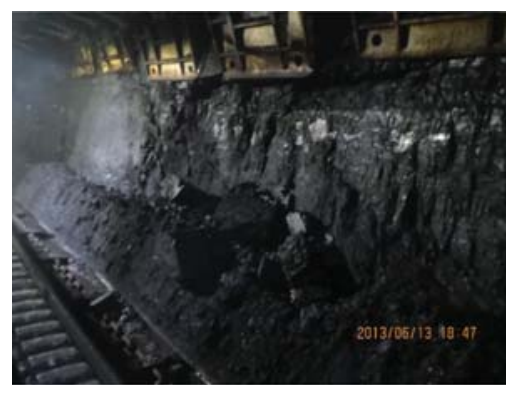

Figure 13-Field controlling work mately arctangent relationship with mining height $M$ (the mining height of mining face no. 104).

By applying theoretical calculations and on-site measurements, the area containing supports 100-120 was identified as a key area for surrounding support rock control work. The graded support control technique was proposed, and was shown to effectively reduce incidences of support malfunction, achieving safe and highly efficient control of strata behaviour in an active mining area.

\section{Acknowledgements}

National Natural Science Foundation of China No. 51234005 and No. 51504259 financially supported by the National Basic Research Program of China under Grant No. 2010CB226802. Fundamental Research Funds for the Central Universities (2010QZ06) are gratefully acknowledged for financial support of the research described in this paper.

\section{References}

Cheng, Y.H., Jiang, F.X., and PAng, J.L. 2012. Research on lateral strata pressure characteristic in goaf of top coal caving in extra thick coal seam and its application. Journal of China Coal Society, vol. 37, no. 7. pp. 1088-1093.

He, F.L., Yang, L.G., XIE, S.R., Zhang, S.B., Xiao, D.C., and Tian, C.Y. 2013. Safe effective key mining technology of fully mechanized face with complex geological conditions. Journal of Mining and Safety Engineering, vol. 30, no. 2. pp. 218-222.

Hou, C.J. and LI, X.H. 2001. Stability theory of integral and local structure with surrounding rock in gob-side tunelling process of fully mechanized caving. Journal of China Coal Society, vol. 26, no. 1. pp. 1-4.

HuANG, Z.Z. 2013. Study on laws of roof strata fracture of fully mechanized caving mining under goaf in ultra thick seam. Coal Science and Technology, vol. 41, no. 7. pp.60-63.

Ju, J.F., Xu, J.L., ZHU, W.B., and WANG, X.Z. 2010. Mechanism of strong strata behaviors during the working face out of the upper dip coal pillar in contiguous seams. Journal of China Coal Society, vol. 35, no. 1. pp. 15-19.

Ju, J.F., Xu, J.L., ZHu W.B., and WANG, L.J. 2013. Mechanism of support crushing while mining out of upper goaf-side coal pillar in close distance seams of Shendong mining area. Chinese Journal of Rock Mechanics and Engineering, vol. 32, no. 7. pp. 1321-1330.

LI, X.H. 2008. Control theory of surrounding rock stability in gob-side tunelling process with fully mechanized caving and its technique. China University of Mining and Technology Press, Xuzhou.

LI, Y.F. and HuA, X.Z. 2012. Mechanical analysis of stability of key blocks of overlying strata for gob-side entry retaining and calculating width of roadside backfill. Rock and Soil Mechanics, vol. 33, no. 4. pp. 1134-1140.

QIAN, M.G., MiU, X.X., HE, F.L., and Liu, C.Y. 1996. Coupling mechanism analysis of stope support and surrounding rock. Journal of China Coal Society, vol. 21 , no. 1. pp. $40-43$.

Wei, D., He, H., QIn, Y.F., FAn, J., and Zhou, P. 2010. Study on mechanism of mining tremor induced by key strata instability in the gob beside the working face. Journal of China Coal Society, vol. 37, no. 7. pp. 1088-1093.

XIE, G.X., YANG, K., and LiU, Q.M. 2006. Study on distribution laws of stress in inclined coal pillar for fully-mechanized top-coal caving face. Chinese Journal of Rock Mechanics and Engineering, vol. 25, no. 3. pp. 545-549.

Xie, S.R., Zhang, G.C., Zhang, S.B., He, F.L., XiAo, D.C., and Tian, C.Y. 2013. Stability control of support-surrounding rock in the large inclination fully mechanized island face. Journal of Mining and Safety Engineering, vol. 30, no. 3. pp. 343-347.

XIE, X.Z. 2012. Study on the characteristics of strata behavior in shallow seam longwall mining under the room-and-pillar mining goaf. Journal of China Coal Society, vol. 37, no. 6. pp. 898-902.

ZHANG, B.S., YANG, S.S., KANG, L.X., and ZHAI, Y.D.. 2008. Discussion on method for determining reasonable position of roadway for ultra-close multi-seam. Chinese Journal of Rock Mechanics and Engineering, vol. 27, no. 1. pp. 97-101.

ZHANG, H.W., Zhang, N., KAn, J.G., Yu, X.Y., and Li, B.Y.. 2010. Stability control technology of surrounding rock in soft seam gateway under goaf. Coal Science and Technology, vol. 38, no. 8. pp. 25-29.

Zhu, T., Zhang, B.S., Feng, G.R., Zhang, X.Y., and Kang, L.X. 2010. Roof structure and control in the lower seam mining field in the ultra-close multiple seams. Journal of China Coal Society, vol. 5, no. 2. pp. 190-193. 